Published in final edited form as:

Occup Environ Med. 2018 November 01; 75(11): 830-836. doi:10.1136/oemed-2018-105114.

\title{
Current research priorities for UK occupational physicians and occupational health researchers: a modified Delphi study
}

\author{
Drushca Lalloo ${ }^{1,{ }^{*}}$, Evangelia Demou ${ }^{2}$, Julia Smedley ${ }^{3}$, Ira Madan ${ }^{4}$, Kaveh Asanati $^{5}$, Ewan. \\ B. Macdonald ${ }^{1}$ \\ ${ }^{1}$ Healthy Working Lives Group, Institute of Health and Wellbeing, College of Medical, Veterinary \\ and Life Sciences, University of Glasgow, G12 8RZ, Glasgow, UK \\ ${ }^{2} \mathrm{MRC} / \mathrm{CSO}$ Social and Public Health Sciences Unit, Institute of Health and Wellbeing, College of \\ Medical, Veterinary and Life Sciences, University of Glasgow, G2 3QB, Glasgow, UK \\ ${ }^{3}$ Occupational Health Department, University Hospital Southampton NHS Foundation Trust, \\ Residence Block 4, MP100, Southampton General Hospital, Tremona Rd, SO16 3YD, \\ Southampton UK * on behalf of the Faculty of Occupational Medicine, London UK \\ ${ }^{4}$ Guy's \& St Thomas' NHS Foundation Trust and King's College London. Occupational Health \\ Department, The Education Centre, St Thomas' Hospital, Westminster Bridge Road, SE1 7EH, \\ London UK. * on behalf of the Faculty of Occupational Medicine, London UK \\ ${ }^{5}$ Imperial College London, National Heart \& Lung Institute, Respiratory Epidemiology, \\ Occupational Medicine and Public Health, Emmanuel Kaye Building, 1b Manresa Road, SW3 \\ 6LR
}

\section{Abstract}

Objectives-Studies identifying national occupational health $(\mathrm{OH})$ research priorities have been conducted in several countries to establish where $\mathrm{OH}$ research should be focused and where funding should be targeted. However, the UK findings are now over 20 years old and $\mathrm{OH}$ practice is continuously evolving. The aim of this study was to identify current research priorities for UK occupational physicians (OPs) and occupational health researchers (OHRs).

Methods-Current research priorities in $\mathrm{OH}$ were identified using a modified Delphi technique. This was conducted in two Rounds to achieve consensus. Research priorities were rated and then ranked using questionnaires developed from expert panel discussions, key research topics identified from the medical literature and participant feedback. Overall and inter-group comparisons were completed for the ranking scores.

\footnotetext{
*Corresponding Author: Dr Drushca Lalloo, Healthy Working Lives Group, Institute of Health and Wellbeing College of Medical, Veterinary and Life Sciences, University of Glasgow, 1 Lilybank Gardens, G12 8RZ, Glasgow, UK, drushca@ hotmail.com, Tel: +44 1413303559.

Competing interests

None to declare.

Ethics approval

Ethics approval to undertake this study was provided by the University of Glasgow, College of Medical, Veterinary \& Life Sciences Ethics Committee [200150143].

Provenance and peer review

Not commissioned; externally peer reviewed
} 
Results-Consensus among OPs and OHRs was high with almost all (9/10) primary domains (PDs) rated as 'very important' or 'absolutely necessary' by more than $54 \%$ of respondents. The research priority areas ranked highest were jointly economic evaluation/cost effectiveness studies and disability management followed by occupational disease/injury/illness.

Occupational health policy, was ranked lowest after sickness absence management and health promotion. The secondary domain (SD) analysis identified priority emphasis on mental health and psychosocial hazards within the workplace and the need to further develop evidence-based guidance for clinical $\mathrm{OH}$ practice.

Conclusions-We identified the current research priorities for UK OPs and OHRs. The findings will inform future national $\mathrm{OH}$ research strategy and support research that addresses important knowledge gaps within $\mathrm{OH}$ and other inter-disciplinary specialties.

\section{Keywords}

research priorities; occupational physician; occupational health researchers; Delphi study

\section{Introduction}

Research plays a pivotal role in progressing the evidence-base for clinical practice in many specialties, including occupational health $(\mathrm{OH})$. An increasingly multi-disciplinary specialty, $\mathrm{OH}$ has been evolving in recent decades with technological advances and changes in work practices/patterns, customer/workforce needs and working population demographics. Consequently, a shift of interest has occurred with a changing focus on health conditions associated with technological advances and the changing workplace, including biopsychosocial factors ${ }^{1}$. In contrast to historical focus on reduction of traditional occupational diseases, the health benefit of 'good' work' is now recognised ${ }^{2}$ with an increased emphasis on promoting health, well-being and improving retention and functioning of people at work ${ }^{3}$. Increasingly, healthcare practitioners, researchers and policymakers are recognising the importance of the workplace as a forum for influencing health behaviours, of work as a clinical outcome and worklessness as a public health issue ${ }^{23}$.

This paradigm shift has presented fresh challenges and changing priorities in $\mathrm{OH}$, including research. $\mathrm{OH}$ research funding is scarce and sponsors expect demonstrated value for money and impact from the resources provided.

National OH research priorities have previously been established in numerous countries ${ }^{4}$ including the USA ${ }^{56}$, Netherlands ${ }^{7}$, Italy ${ }^{89}$, Japan ${ }^{10}$, Malaysia ${ }^{11}, \mathrm{UAE}^{12}$, Australia ${ }^{13}$ and the United Kingdom (UK) ${ }^{1415}$. European studies have also been undertaken ${ }^{16}$, more recently to inform a European research agenda ${ }^{17}$ as well as a global study ${ }^{18}$. Identified priorities have focussed on cost-benefit studies ${ }^{716}$, workplace injuries ${ }^{913}$, occupational carcinogenesis ${ }^{9}$, psychosocial hazards ${ }^{13}$ and changing work patterns/workforce ${ }^{1017}$. In earlier UK studies, musculoskeletal disorders were the highest priority among $\mathrm{OH}$ clinicians ${ }^{14}$ with musculoskeletal disorders and stress, top in a study of personnel managers ${ }^{15}$. As these studies highlight ${ }^{4-18}$, national priorities vary between countries ${ }^{4-18}$ given differences in economic development, socio-cultural backgrounds, health \& safety regulation and work/ 
workforce demographics. In the UK work/workforce demographics and regulatory/ legislative requirements have changed in recent decades. Understanding current national research priorities is essential to target funding and ensure research is relevant and impactful on an academic, policy and practical level.

The importance of these studies is evident from the impact they had within their countries ${ }^{19}$. After occupational carcinogenesis was assigned top priority in the Italian study (2001), the Italian Health Ministry prioritised research funding on this subject, allocating 33\% of the budget to this topic ${ }^{19}$. Similar outcomes have been described from the European and U.S. studies ${ }^{19}$. Following the UK study ${ }^{14}$ (1994), the British Occupational Health Research Fund assigned a large proportion of its budget to the highest priority in that study i.e. musculoskeletal disorders and rehabilitation techniques ${ }^{19}$. However, the UK findings ${ }^{14}$ are now over 20 years old.

Achieving consensus on current research priorities will inform the future direction of national $\mathrm{OH}$ research strategy, support and encourage research that addresses important knowledge gaps, and identify where to target funding. This study's aim is to establish the research priorities of UK occupational physicians (OPs) and occupational health researchers (OHRs), using a modified Delphi technique.

\section{Methods}

\section{Step 1}

This study was requested by the UK Faculty of Occupational Medicine (FOM) Research Strategy Working Group (RSWG) established in 2014 to formulate a long-term national $\mathrm{OH}$ research strategy. Consequently, the study focus was on OPs. Recognising that $\mathrm{OH}$ research is multi-disciplinary and conducted by many academics who are not OPs, we also included OHRs. A previous systematic review ${ }^{4}$ identified that the Delphi technique has been extensively and effectively used to establish $\mathrm{OH}$ research priorities across countries and participant backgrounds. The Delphi technique is an iterative process comprising a series of questionnaires starting with open-ended broad questions ${ }^{41420}$. The process stops when consensus is established at a sufficient level on the key priorities. When information on the topic is already available, the use of a modified Delphi technique (e.g. commencing at more advanced stages) is proposed as an appropriate option ${ }^{21}$. The existing body of international literature on $\mathrm{OH}$ research priorities ${ }^{4-18}$ justified applying the modified technique ${ }^{420}$ in this study. Our modified Delphi technique, ${ }^{2223}$ is described in Figure 1.

Series of expert panel (OPs and OHRs from RSWG) discussions alongside a review of the medical literature were undertaken to identify current and emerging $\mathrm{OH}$ research topics. This strategy and the findings informed the development of the questionnaire. Primary domains (PDs) covering broad research fields were established and within each of these, secondary domains (SDs) describing more specific items (Figure 1). The study was conducted in two Rounds, Round 1- 'rating' and Round 2 -'ranking'. The 'ranking' round defines the top research priorities. 
In addition to the UK FOM, contacts were established with the UK Society of Occupational Medicine (SOM) and key members of UK Academic OH institutions. These groups agreed to participate and disseminate the questionnaire among their respective memberships/ departments. It was recognised that there are a number of physicians and researchers working in the field of $\mathrm{OH}$ that are not necessarily affiliated with a specialty-specific body or $\mathrm{OH}$ academic institution. Furthermore, the key role of e-newsletters and professional networking media in distributing the questionnaire nationally became apparent. Therefore, we elected to distribute through this method as well as conventional $\mathrm{OH}$ organisations/ academic institutions membership lists. This facilitated a wider distribution and broader range of responses, although did not allow for establishing a response rate. Links to the questionnaires and information sheet were circulated via electronic mail and e-newsletters using an online survey programme (SMART survey TM). Both questionnaires were piloted by eight senior OPs and OHRs, for language, comprehension and ease of use and changes made accordingly. After reading the information sheet, participants were asked to provide their informed (online) consent to proceed with questionnaire completion.

\section{Step 2 - Round 1 'Rating' Questionnaire}

The questionnaire included $10 \mathrm{PDs}$ covering an extensive range of $\mathrm{OH}$ research and practice areas and within these, the SD items ranged from four to thirteen. Following the pilot phase, the Round 1 (rating) questionnaire was circulated and respondents were asked to 'rate' the relative importance of the research topics on a scale of 1 (=of least importance) to 5 (=absolutely necessary) ${ }^{23}$. Using a free text question at the end of each PD, respondents could add items they considered important, and not already covered. The 'rating' step results determine how many rounds are required to establish consensus to proceed to the final ranking round. In this study the number of rounds was not set a priori. However, as established from multiple previous studies, when applying a modified version, two Delphi rounds are often adequate to establish consensus on the key priorities 811172223 .

\section{Step 3 - Round 2 'Ranking’ Questionnaire}

The first round responses informed the content and modification of the 'rating' questionnaire in order to then 'rank' the items (Round 2). The original 10 PDs and related SDs were retained, and new SD items derived from the first round open-ended question responses were added. This ranking questionnaire was sent to the same key contacts of Round 1 for distribution to their networks. OPs and OHRs could participate even if they had not taken part in Round 1. Respondents were now requested to 'rank' PDs and respective SDs. The item considered most important was ranked 1, next most important 2 and so on. In any given domain, it was not permitted to give 2 items the same score.

Average mean rank scores were obtained for each PD and SD. In view of the wide range of SDs per PD, mean scores were standardised to a 1-10 scale, to allow direct comparison of the relative importance of SDs across PDs and overall.

Respondents were asked to self-select whether they were - OP (if they were a medical practitioner and undertaking clinical $\mathrm{OH}$ practice), OP \& OHR (if in addition to the above, they had an academic role) and OHR (if they were non-medical and involved in $\mathrm{OH}$ 
research). Current $\mathrm{OH}$ practice areas comprised work in healthcare settings, for example hospitals (healthcare), public/private sector organisations (industry), participation in teaching or research (academic) or any work sector not covered by these (other). More than one category could be selected for sector. Inter-group (age, sex, years of experience, country) comparisons of the group ranking were performed using the Spearman's rank test.

Concerns around the so-called 'practitioner-researcher divide' 24 and 'research-practice gaps' ${ }^{25}$ within $\mathrm{OH}$ and safety have been reported ${ }^{26}$. These focus on the degree to which researchers address questions of primary importance to them (rather than practitioner-based research ${ }^{27}$, the perception that academic research findings rarely transfer into practice or policy changes ${ }^{2425}$, and questioning the value practitioners place on research ${ }^{27}$. However, it has been proposed that if published research is seen as relevant and useful, there is a higher likelihood practitioners will read it and the findings will influence their practice ${ }^{27}$.

Informal feedback at the inception of this study indicated a perception among some OPs, that research ideas are primarily generated and led by academics. Despite being at the 'coalface' of $\mathrm{OH}$ practice, often with first-hand exposure to gaps in the knowledge base and being expected to translate the evidence into practice, they perceived less of an influence on research studies. Therefore, this study was inclusive of academics and all practising OPs. The participation sheet acknowledged that at first glance, the questions may not seem relevant to OP respondents. However, we highlighted that their responses could be for their research priorities in general but also specific research topics or studies they might find informative for their own day-to-day practice.

The first 'rating' round was completed September-November 2016 and the second 'ranking' round February-June 2017. Approximately, one month after distributing both questionnaires, two reminder emails were sent to increase response rates. The data was analysed using $\mathrm{R}$. Ethical approval was obtained by the University of Glasgow, College of Medical, Veterinary \& Life Sciences Ethics Committee [200150143].

\section{Results}

\section{Round 1- Rating}

252 responses to the first questionnaire were received. The demographic distribution of responses is presented in Table 1.

Responses were received from all four UK countries with some individuals working across more than one country. The majority of respondents were male (62.6\%), aged 45-64 $(66.2 \%)$ and OPs $(73.4 \%)$.

For the physician groups (OP,OP \& OHR), who were able to select more than one area of clinical practice, the main areas reported were other $(75 \%)$ and healthcare $(75 \%)$ followed by industry (59.5\%). The results of the 'rating' round are presented in Table 2.

Consensus among OPs and OHRs was high with 9 out of 10 PDs scoring above 54\% in rating as 'very important' or 'absolutely necessary'. Analysing the sum of scores for these two higher level rating categories, occupational disease/injury/illness (87.7\%), scored 
highest, followed by occupational hazards to health and risk assessment (82.9\%) and economic evaluation/cost-effectiveness studies $(78.6 \%)$. Health promotion scored lowest $(49.2 \%)$. Therefore, consensus was deemed sufficient to proceed to the final and definitive 'ranking' phase.

New SD items from the free-text questions were collated, grouped by theme and new items not covered in some form were included in the ranking round. We received 97 responses across the PDs. Nine SDs not already covered were added in 4 different PD sections and included: Quality and characteristics of managers/management style and impact on return to work outcomes; role of vocational occupational therapy (OT) in return to work (occupational rehabilitation); remote/online/telephone consultations; resilience; managing embitterment (the changing nature of work); reasonable adjustments and employer engagement; evidencebased guidance on work accommodations (disability management); evaluation of the effectiveness of $\mathrm{OH}$ services/making the business case for $\mathrm{OH}$; linking $\mathrm{OH}$ with mainstream healthcare (occupational health policy). These findings highlight developing areas not described in most previous studies notably; the OT role in vocational rehabilitation, the evidence around workplace adjustments, and management style and quality on return-towork outcomes.

\section{Round 2 - Ranking}

196 responses to Round 2 were received (Table 1). Responses were received from all four UK countries; with some overlap evident. The majority of respondents were male (58.7\%), aged 45-64 (67.5\%) and OPs (68.6\%). For the physician groups (OP, OP \& OHR), who were able to select more than one area of clinical practice, the main area reported was other (79.6\%), followed by healthcare $(79.1 \%)$ and industry $(58.7 \%)$.

Subgroup analyses by age, gender and years of experience using the Spearmans rank test identified that the rankings were not statistically different at the $99 \%$ confidence level for these demographic categories. Using the same correlation test, we tested for regional differences between countries in the ranking of the PDs. Where sample size allowed for analysis, no statistically significant differences were seen by country.

Comparing respondents of the first and second Rounds, no significant differences in the distributions of gender (Fisher exact test $\mathrm{p}=0.62)$, age group $(\mathrm{p}=0.26)$, job practice $(\mathrm{p}=0.34)$, country $(\mathrm{p}=0.25$ ), years of experience (independent $\mathrm{t}$-test, $\mathrm{t}$-value $=-1.47, \mathrm{p}=0.14$ ) were identified.

The final Round 2 'ranking' results define the top research priorities (Table 3). The standardised mean score reports the consensus of priority, with low scores indicating high priority and high scores indicating low priority.

In this round, economic evaluation/cost-effectiveness studies and disability management were jointly ranked most important, followed by occupational disease/injury/illness.

Occupational health policy was ranked lowest after sickness absence management and health promotion. Figure 2 demonstrates the variation in ranks. There is a higher level of agreement on importance between PDs ranked 1-2 and 8-10 with more variation evident between PDs 
ranked 3-7. Between OPs and OHRs, greatest divergence in PD ranks (difference of more than 3 ranks) were occupational rehabilitation and health services research. PD ranks between OPs and OP \& OHRs were generally similar but with a noted divergence in occupational rehabilitation. In both comparisons, occupational rehabilitation was ranked higher by OPs.

Table 3 also presents the top scoring SDs within each PD, where psycho-social factors, evidence-based guidelines and effectiveness of interventions are key priority themes.

Separately, in both rounds, respondents were asked to select research areas they are currently or have recently been involved in from the PD categories. This would allow comparison between key areas in which UK research is currently being undertaken and our research priorities findings. The most commonly cited current research areas were occupational disease/injury/illness, followed by occupational hazards to health and risk assessment and then sickness absence management.

\section{Discussion}

\section{Summary of findings}

This study identified current research priorities for UK OPs and OHRs. Economic evaluation/cost-effectiveness studies and disability management were identified jointly as the top research priority followed by occupational disease/injury/illness.

These findings reflect the paradigm shift in $\mathrm{OH}$, and the management of disability as a key function of modern $\mathrm{OH}$ practice. Undoubtedly, the introduction of UK disability discrimination legislation in $1995^{2829}$ is an important contributing factor. This places an onus on employers to consider reasonable workplace adjustments to assist disabled employees. Although ultimately a legal decision, OPs are routinely consulted by employers for their opinions on applicability and potential workplace adjustments.

The joint more 'value-for-money', service-based priority could reflect the high proportion of OPs compared to academic respondents. However, if a research goal is to drive evidencebased clinical practice, then clinician's views are relevant. Our findings support the changing $\mathrm{OH}$ landscape where $\mathrm{OH}$ clinicians are increasingly having to prove their worth and economic value to customers ${ }^{30}$ and effectively, make the business case for $\mathrm{OH}^{3132}$. This is supported by the highest ranked subsection in that domain 'cost benefit analyses of $\mathrm{OH}$ services'. Evaluation of the effectiveness of $\mathrm{OH}$ service provision was specifically highlighted in Dame Carol Black's 2008 review of the health of the UK's working-age population ${ }^{3}$. Its importance is also described as a means of ensuring that already scarce $\mathrm{OH}$ resources are utilised effectively and of developing an evidence-base for service standards and accreditation ${ }^{33}$. A $1999 \mathrm{OH}$ services evaluation research review identified that most published studies were lacking in methodological quality, being predominantly descriptive rather than evaluative ${ }^{34}$. Recent publications ${ }^{3135}$ highlight this as a persisting problem and appeal to the $\mathrm{OH}$ research community for high quality evaluation studies to strengthen the value proposition for $\mathrm{OH}$ services ${ }^{36}$. 
Occupational health policy was the lowest ranked PD. Sickness absence management as second lowest may reflect perceptions among OPs of this being fundamentally a human resources function with $\mathrm{OH}$ providing medical input or also an area in which, there is already an abundance of established research.

Analysis of the highest ranked SDs showed a priority emphasis on mental health and psychosocial hazards, featuring top in two PDs. This supports the changing landscape, of mental ill-health, (including work-related mental ill-health) as a prominent disease of current times $^{37}$. Musculoskeletal issues are absent among top priorities, although this was the highest priority in the previous UK study 20 years ago ${ }^{14}$. The overarching theme of a need/ requirement for an increase in evidence-based guidance for clinical $\mathrm{OH}$ practice was also identified.

Comparison of our findings with respondents' most frequently reported current research areas highlighted disparities between areas in which research is currently being undertaken (occupational disease/injury/illness, occupational hazards to health and risk assessment and sickness absence management) and areas where current priorities were identified (economic evaluation/cost-effectiveness studies and disability management). This may reflect emphasis on 'higher profile' aetiological and intervention studies within the $\mathrm{OH}$ research agenda ${ }^{33}$; publication bias; or related to research funding schemes, the criteria they apply and specific study types awarded grants. In the UK a limited number of organisations fund $\mathrm{OH}$ research. Most commonly, $\mathrm{OH} /$ work-related research is funded as part of large multi-disciplinary UK Research and Innovation schemes, making it difficult to quantitate total research funding allocation to $\mathrm{OH}$ priority areas. National research funders seek advice on $\mathrm{OH}$ priority areas from the James Lind Alliance and the Faculty of Occupational Medicine. The diminishing UK OH research centres and academic base ${ }^{3839}$ are concomitant challenges in progressing the research agenda. Initiatives such as the recent establishment of the FOM Academic Forum, open to anyone involved in occupational or workplace health research, are crucial steps towards establishing/consolidating the research base and progressing research in the field.

\section{Strengths and limitations}

The research priorities are derived from both UK OPs and non-medical $\mathrm{OH}$ researchers, which is novel compared to the previous UK study ${ }^{14}$ (that only included OPs) and other similar studies which included only one of these groups ${ }^{17}$. Restricting it to OPs limits the perspective to predominantly a clinical one. Conversely, researcher-only studies have a tendency to promote their own research activities as priorities, which is also a limiting factor ${ }^{17}$. Therefore, this mixed approach facilitated a broader scope of consensus. Furthermore, the priorities in this study are derived from the opinions and experience of OPs working across the UK and different employment sectors and from other published similar studies.

The lower response rate to the second round could be considered a study weakness. However, challenges of maintaining response rates in successive iterations during the Delphi process are recognised ${ }^{21}$. Survey fatigue among OPs may have contributed due to other 
specialty-related surveys disseminated during this period, which we could neither predict nor control.

Underrepresentation of some UK countries particularly Northern Ireland and Wales is evident, potentially limiting the breadth of comparisons. This could reflect smaller OP and OHR populations in these countries. Our study identified that a number of OPs work across multiple countries and assessing priorities in the context of regional variations should account for this important factor.

Due to the survey dissemination and participant recruitment method used estimating a response rate was not possible. This approach however, has enabled our survey to reach the wider UK OP and OHR community, facilitating a more broadly representative and diverse range of responses.

\section{Comparison with previous studies}

Direct comparison of priority areas established in previous studies ${ }^{4-18}$, particularly from other countries is difficult, for the reasons described above, which inherently will result in contrasting priorities. There is also substantial variation by methodology and classification of priority topics, some with highly specific and others with broader topics. Although the categorisation and level of detail are different, the top priority is clearly identifiable. Our highest ranking domain is consistent with results from The Netherlands ${ }^{7}$ and the earlier European study ${ }^{16}$ where cost-benefit studies were top priorities; but findings differ from similar Italian ${ }^{89}$, Malaysian ${ }^{11}$, Japanese ${ }^{10}$ and the recent European ${ }^{17}$ studies where health surveillance/work organisation, workplace injuries, occupational carcinogenesis, specific occupational groups/industries and changing work patterns/workforce were top priorities. The difference in our findings from the previous UK study ${ }^{14}$ (where musculoskeletal disorders were the highest priority) likely reflect modern, evolving $\mathrm{OH}$ practice. Key features within this, supported by our results, are the increasing mental health epidemic ${ }^{37}$ and increasing emphasis on psychosocial workplace hazards ${ }^{40}$, which correlates with the Australian findings ${ }^{13}$.

\section{Conclusion}

This study has demonstrated differences from UK research priorities identified 20 years ago, a likely reflection of evolving $\mathrm{OH}$ practice and related legislation. A recent editorial on the future of occupational medicine $\mathrm{e}^{30}$ highlighted the need for a national and/or international research strategy. Our findings provide stakeholders with the necessary information for the development of the future UK OH research strategy and can inform international priorities in $\mathrm{OH}$ research. Key next steps are identifying the relevant research questions within these perceived priority areas and identifying resources for implementing the research.

\section{Acknowledgements}

The authors wish to thank their UK OP and OHR colleagues who distributed and completed the questionnaires. We also would like to thank Funbi Ogundipe, Christopher Ide, Damien McIlvenney, Jennifer Schreiber, Judith Brown and Joanne Neary for their contributions. A very special thanks to Richard Heron (Past President of the Faculty of Occupational Medicine) and Nick Pahl (CEO of the Society of Occupational Medicine) for their continued support of this study. 
Funding

E. Demou was supported by the Medical Research Council (partnership grant MC/PC/13027).

\section{References}

1. Lunt J, Fox D, Bowen J, et al. Applying the Biopsychosocial Approach to Managing the Risks of Contemporary Occupational Health Conditions: Scoping Review. HSL/2007/24. 2007Accessed 16 May 2018

2. DOH. DWP. [Accessed 16 May 2018] Improving Lives The Future of Work, Health and Disability. 2017. [online] Available at: https://www.gov.uk/government/uploads/system/uploads/ attachment_data/file/66339 9/improving-lives-the-future-of-work-health-and-disability.PDF

3. Black, C. Working for a healthier tomorrow.2008. Office of Public Sector Information; Norwich: 2008. [online] Available at: https://www.gov.uk/government/uploads/system/uploads/ attachment_data/file/209782/hwwb-working-for-a-healthier-tomorrow.pdf [Accessed 16 May 2018]

4. Iavicoli S, Rondinone B, Marinaccio A, Fingerhut M. Research priorities in occupational safety and health: a review. Ind Health. 2006; 44:169-78. [PubMed: 16610556]

5. NIOSH (NORA). [Accessed 16 May 2018] National Occupational Research Agenda: Second Decade in Review | 2006-2016. 2017. Publication Number 2017-146 https://www.cdc.gov/niosh/ docs/2017-146/

6. Rosenstock L, Olenec C, Wagner GR. The National Occupational Research Agenda: a model of broad stakeholder input into priority setting. Am J Public Health. 1998; 88:353-6. [PubMed: 9518963]

7. van der Beek AJ, Frings-Dresen MH, van Dijk FJ, Houtman IL. Priorities in occupational health research: a Delphi study in The Netherlands. Occup Environ Med. 1997; 54:504-10. [PubMed: 9282128]

8. Iavicoli S, Marinaccio A, Vonesch N, Ursini CL, Grandi C, Palmi S. Research priorities in occupational health in Italy. Occup Environ Med. 2001; 58:325-9. [PubMed: 11303082]

9. Rondinone BM, Boccuni F, Iavicoli S. Trends and priorities in occupational health research and knowledge transfer in Italy. Scand J Work Environ Health. 2010; 36:339-48. [PubMed: 20066387]

10. Araki S, Tachi M. National occupational health research priorities, agenda and strategy of Japan: invited report in NORA symposium 2001, USA. Ind Health. 2003; 41:49-54. [PubMed: 12674554]

11. Sadhra S, Beach JR, Aw TC, Sheikh-Ahmed K. Occupational health research priorities in Malaysia: a Delphi study. Occup Environ Med. 2001; 58:426-31. [PubMed: 11404445]

12. Aw, T-C. Occupational Health and Safety priorities for the United Arab Emirates. A report to the Health Authority Abu Dhabi; Abu Dhabi, United Arab Emirates: 2010.

13. Smith DR. Establishing national priorities for Australian occupational health and safety research. J Occup Health. 2010; 52:241-8. [PubMed: 20460832]

14. Harrington JM. Research priorities in occupational medicine: a survey of United Kingdom medical opinion by the Delphi technique. Occup Environ Med. 1994; 51:289-94. [PubMed: 8199676]

15. Harrington JM, Calvert IA. Research priorities in occupational medicine: a survey of United Kingdom personnel managers. Occup Environ Med. 1996; 53:642-4. [PubMed: 8882122]

16. European Agency for Safety and Health at Work B. Future Occupational Safety and Health Research Needs and Priorities in the Member States of the European Union. 2000

17. Gagliardi D, Rondinone BM, Mirabile M, et al. The perspective of European researchers of national occupational safety and health institutes for contributing to a European research agenda: a modified Delphi study. BMJ Open. 2017; 7:e015336.

18. Fingerhut M, Kortum-Margot E. Network of WHO Collaborating Centres in Occupational Health,communication and information dissemination. Asian-Pacific Newsletter on Occupational Health and Safety (2003). 2002; 9:28-30.

19. Iavicoli S, Rondinone B, Marinaccio A, Fingerhut M. Identification of research priorities in occupational health. Occup Environ Med. 2005; 62:71-2. [PubMed: 15657185] 
20. Linstone, H, T, M. The Delphi Method: Techniques and applications. Addison Wesley Publishing; 1975.

21. Hsu CC, S B. Minimizing non-response in the Delphi process: how to respond to non-response. Pract Assess Res Eval. 2007; 12:62-78.

22. Lalloo D, Demou E, Kiran S, Cloeren M, Mendes R, Macdonald EB. International perspective on common core competencies for occupational physicians: a modified Delphi study. Occup Environ Med. 2016; 73:452-8. [PubMed: 27076063]

23. Macdonald EB, Ritchie KA, Murray KJ, Gilmour WH. Requirements for occupational medicine training in Europe: a Delphi study. Occup Environ Med. 2000; 57:98-105. [PubMed: 10711277]

24. Anderson N, Herriot P, Hodgkinson GP. The practitioner-researcher divide in Industrial, Work and Organizational (IWO) psychology: Where are we now, and where do we go from here? Journal of Occupational and Organizational Psychology. 2001; 74:391-411.

25. Chung AZQ, Shorrock ST. The research-practice relationship in ergonomics and human factors surveying and bridging the gap. Ergonomics. 2011; 54:413-429. [PubMed: 21547787]

26. Waterson P. Bridging the gap between research, policy and practice in health and safety. Policy and Practice in Health and Safety. 2016; 14(2):97-98.

27. Cascio WF, Aguinis H. Research in industrial and organizational psychology from 1963 to 2007 : Changes, choices, and trends. Journal of Applied Psychology. 2008; 93:1062-1081. [PubMed: 18808226]

28. Crown. [Accessed 16 May 2018] Disability Discrimination Act 1995. [online] Available at: http:// www.legislation.gov.uk/ukpga/1995/50/introduction

29. Crown. [Accessed 16 May 2018] Equality Act 2010: (Guidance on the Definition of Disability). [online] Available at: http://www.legislation.gov.uk/uksi/2011/1159/made

30. Nicholson PJ. Occupational medicine: new world, new definition. Occupational Medicine-Oxford. 2001; 51:423-424.

31. Nicholson PJ. Occupational health: the value proposition. Society of Occupational Medicine London. 2017

32. Verbeek J, Pulliainen M, Kankaanpaa E. A systematic review of occupational safety and health business cases. Scand J Work Environ Health. 2009; 35:403-12. [PubMed: 19806275]

33. Sim MR. Occupational health services--standards need to be underpinned by better research on effectiveness. Occup Environ Med. 2010; 67:289-90. [PubMed: 20447984]

34. Hulshof CT, Verbeek JH, van Dijk FJ, van der Weide WE, Braam IT. Evaluation research in occupational health services: general principles and a systematic review of empirical studies. Occup Environ Med. 1999; 56:361-77. [PubMed: 10474531]

35. Uegaki K, de Bruijne MC, Lambeek L, et al. Economic evaluations of occupational health interventions from a corporate perspective - a systematic review of methodological quality. Scand J Work Environ Health. 2010; 36:273-88. [PubMed: 20473477]

36. Nicholson PJ. Occupational medicine: paradise lost. Occupational Medicine-Oxford. 2017; 67:507-509.

37. Office for National Statistics. Sickness Absence in the Labour Market, 2014. ONS Newport. 2014

38. Harrington JM, Seaton A. A payroll tax for occupational health research? Br Med J (Clin Res Ed). 1988; 296:1618.

39. Blain PG. Occupational health research. BMJ. 1988; 297:1043-4.

40. The British Psychological Society. [Accessed 16 May 2018] Working Group on Health and Wellbeing in the Workplace. White Paper - Psychological well-being at work. 2010. [online] Available at: https://www1.bps.org.uk/system/files/user-files/Division\%20of\%20Occupational \%20Psychology/public/rep94_dpx.pdf 


\section{'What this paper adds'}

\section{What is already known about this subject?}

- Studies identifying national occupational health $(\mathrm{OH})$ research priorities have been conducted in several countries. However, the UK findings are now over 20 years old.

\section{What are the new findings?}

- This study has identified current research priorities for UK OPs and $\mathrm{OH}$ researchers with demonstrated differences from those previously identified, a likely reflection of evolving $\mathrm{OH}$ practice.

- 'Economic evaluation/cost effectiveness studies' and 'disability management' were jointly the top research priority, with emphasis on work related mental health and psychosocial factors on analysis of the more specific secondary domains.

How might this impact on policy or clinical practice in the foreseeable future?

- $\quad$ These findings can inform the future direction of national $\mathrm{OH}$ research strategy and establish where current $\mathrm{OH}$ research and funding ought to be targeted. 


\section{STEP 1}

Expert panel discussions (UK Faculty of Occupational Medicine Research Strategy Working Group)

Literature review - including similar studies

Synthesis from above of key $\mathrm{OH}$ research areas into broad categories (primary domains PDs) and more detailed secondary domains (SDs) for questionnaire development.

STEP 2

'Rating' of items in questionnaire compiled in STEP 1 using Likert scale and allow addition of new items. (ROUND 1)

By consensus PDs and SDs defined.

New subsections added for next step.

Assess whether sufficient consensus achieved and need for further iterations of the rating round.

STEP 3

Original questionnaire adapted in order to 'rank' the items compiled in STEP 2 for priority. (ROUND 2)

\section{RESULTS}

Consensus reached for top research priorities by PDs and also SDs within each given domain and overall.

Figure 1.

Description of modified Delphi process 


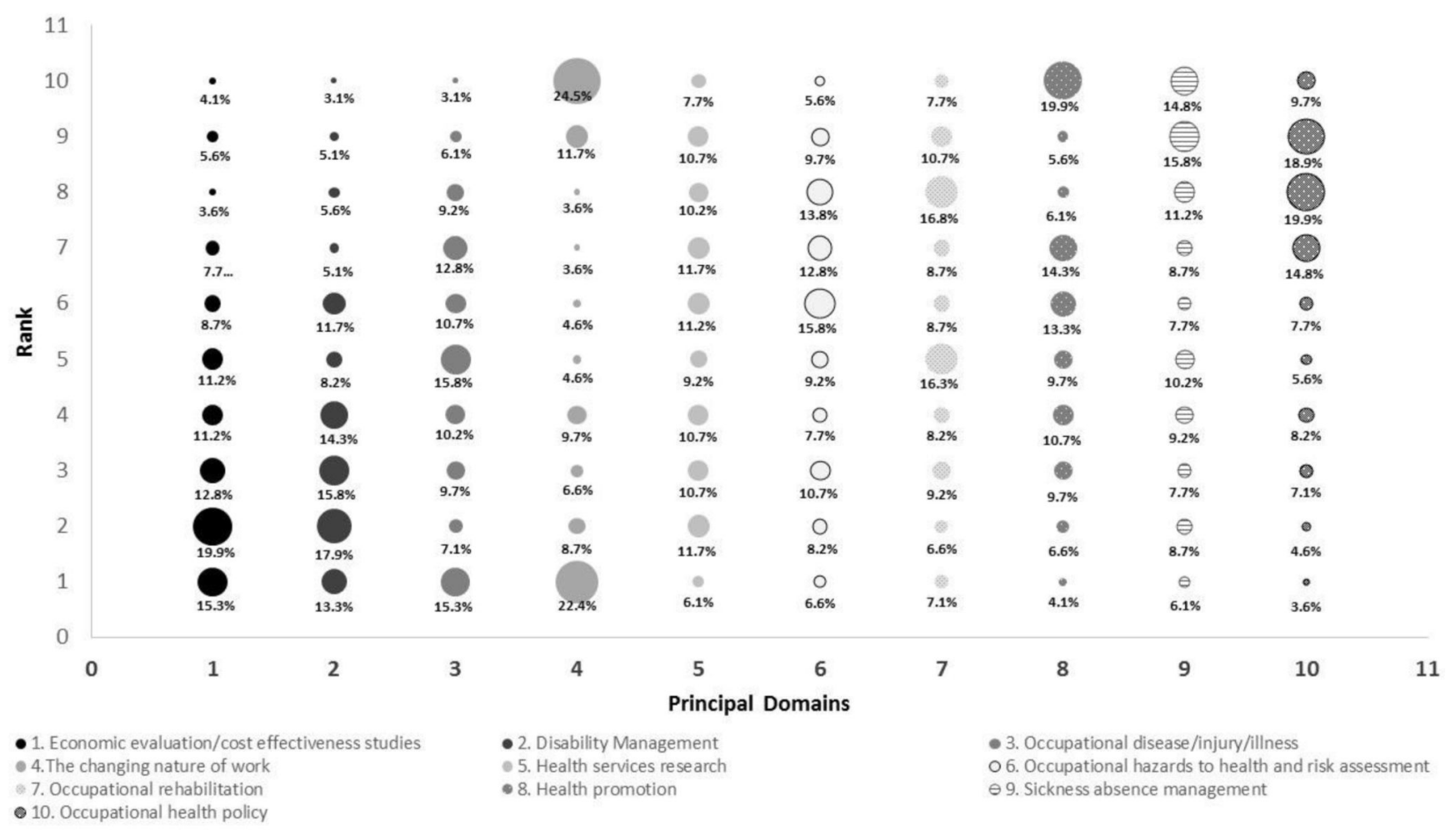

Figure 2.

Ranked primary domains by weighted standardised rank score. Bubble graph demonstrates the variation in ranks given by the survey participants with the size of the bubble indicating the percentage of respondents within each PD that gave it a specific rank. X-axis in order from most highly ranked PD to lowest rank. 


\section{Table 1}

Responses $^{a}$ by age, sex, country, job title and years of experience for Rounds 1 and 2.

\begin{tabular}{|c|c|c|c|c|}
\hline \multirow{2}{*}{$\begin{array}{l}\text { Features } \\
\text { Age range category }\end{array}$} & \multicolumn{2}{|c|}{ Round $1(n=252)$} & \multicolumn{2}{|c|}{ Round 2 (n=196) } \\
\hline & Frequency & $\%$ & Frequency & $\%$ \\
\hline $18-24$ & 1 & 0.4 & 0 & 0.0 \\
\hline $25-34$ & 5 & 2.0 & 9 & 4.1 \\
\hline $35-44$ & 49 & 19.4 & 28 & 13.9 \\
\hline $45-54$ & 83 & 32.9 & 57 & 29.4 \\
\hline $55-64$ & 84 & 33.3 & 74 & 38.1 \\
\hline $65-74$ & 30 & 11.9 & 28 & 14.4 \\
\hline Total & 252 & 100 & 196 & 100 \\
\hline \multicolumn{5}{|l|}{ Sex } \\
\hline Male & 158 & 62.6 & 115 & 58.7 \\
\hline Female & 92 & 36.5 & 80 & 40.8 \\
\hline Missing/prefer not to answer & 2 & 0.8 & 1 & 0.5 \\
\hline Total & 252 & 100 & 196 & 100 \\
\hline \multicolumn{5}{|l|}{ Countries } \\
\hline England & 190 & 75.7 & 142 & 69.3 \\
\hline Northern Ireland & 9 & 3.6 & 7 & 3.4 \\
\hline Scotland & 40 & 15.9 & 48 & 23.4 \\
\hline Wales & 12 & 4.8 & 8 & 3.9 \\
\hline Total & 251 & 100 & $205^{* * *}$ & 100 \\
\hline \multicolumn{5}{|l|}{ Job Title } \\
\hline $\mathrm{OP}^{*}$ & 185 & 73.4 & 135 & 68.6 \\
\hline $\mathrm{OHR}^{* *}$ & 39 & 15.5 & 41 & 21.1 \\
\hline $\mathrm{OP}^{*} \& \mathrm{OHR}$ & 28 & 11.1 & 20 & 10.3 \\
\hline Total & 252 & 100.0 & 196 & 100.0 \\
\hline Years of experience & \multicolumn{2}{|c|}{$\begin{array}{c}\text { Mean } \pm \text { SD }(\min -\mathbf{m a x}) \mathbf{n}=\mathbf{2 1 3} \\
20.4 \pm 11.2(1-60)\end{array}$} & \multicolumn{2}{|c|}{$\begin{array}{c}\text { Mean } \pm \text { SD }(\min -\mathbf{m a x}) \mathbf{n}=\mathbf{1 5 5} \\
21.8 \pm 10.5(1-50)\end{array}$} \\
\hline
\end{tabular}

${ }^{a}$ Response rate cannot be calculated as denominator data was not available due to survey dissemination and participant recruitment method used (See Methods section)

*P: occupational physician

*** OHR: occupational health researcher

*** Note that total answers for country amount to 205 due to individuals working across more than one country 
PD 'Rating' (Round 1)

Table 2

\begin{tabular}{|c|c|c|c|c|c|c|}
\hline & $\begin{array}{l}\text { Primary Domain } \\
\text { RATING scores }(n=252)\end{array}$ & $\begin{array}{l}1 *(\text { of least } \\
\text { importance }) n \\
(\%)\end{array}$ & $\begin{array}{l}2 *(\text { slightly } \\
\text { important }) \mathbf{n} \\
(\%)\end{array}$ & $\begin{array}{l}3^{*}(\text { of average } \\
\text { importance }) n \\
(\%)\end{array}$ & $\begin{array}{l}4^{*}(\text { very } \\
\text { important }) n \\
(\%)\end{array}$ & $\begin{array}{l}5^{*}(\text { absolutely } \\
\text { necessary) n }(\%)\end{array}$ \\
\hline A. & $\begin{array}{l}\text { Occupational disease / } \\
\text { injury/ illness }\end{array}$ & $3(1.2 \%)$ & $3(1.2 \%)$ & $25(9.9 \%)$ & $104(41.3 \%)$ & $117(46.4 \%)$ \\
\hline B. & $\begin{array}{l}\text { Occupational hazards to } \\
\text { health and risk assessment }\end{array}$ & $3(1.2 \%)$ & $8(3.2 \%)$ & $32(12.7 \%)$ & $92(36.5 \%)$ & $117(46.4 \%)$ \\
\hline $\mathrm{C}$ & $\begin{array}{l}\text { Economic evaluation/cost } \\
\text { effectiveness studies }\end{array}$ & $7(2.8 \%)$ & $5(2 \%)$ & $42(16.7 \%)$ & $120(47.6 \%)$ & $78(31 \%)$ \\
\hline D. & $\begin{array}{l}\text { Occupational } \\
\text { rehabilitation (including } \\
\text { return to work after } \\
\text { sickness absence) }\end{array}$ & $8(3.2 \%)$ & $4(1.6 \%)$ & $46(18.3 \%)$ & $102(40.5 \%)$ & $92(36.5 \%)$ \\
\hline E. & $\begin{array}{l}\text { The changing nature of } \\
\text { work (including types of } \\
\text { work and technology } \\
\text { changes }\end{array}$ & $6(2.4 \%)$ & $7(2.8 \%)$ & $49(19.4 \%)$ & $134(53.2 \%)$ & $56(22.2 \%)$ \\
\hline $\mathrm{F}$. & $\begin{array}{l}\text { Sickness absence } \\
\text { management }\end{array}$ & $7(2.8 \%)$ & $9(3.6 \%)$ & $59(23.4 \%)$ & $101(40.1 \%)$ & $76(30.2 \%)$ \\
\hline G. & Disability management & $8(3.2 \%)$ & $7(2.8 \%)$ & $65(25.8 \%)$ & $111(44.1 \%)$ & $61(24.2 \%)$ \\
\hline $\mathrm{H}$. & Health services research & $12(4.8 \%)$ & $14(5.6 \%)$ & $87(34.5 \%)$ & $92(36.5 \%)$ & $47(18.7 \%)$ \\
\hline I. & Occupational health policy & $10(4 \%)$ & $16(6.4 \%)$ & $89(35.3 \%)$ & $92(36.5 \%)$ & $45(17.9 \%)$ \\
\hline $\mathrm{J}$. & Health promotion & $24(9.5 \%)$ & $38(15.1 \%)$ & $66(26.2 \%)$ & $86(34.1 \%)$ & $38(15.1 \%)$ \\
\hline
\end{tabular}

$1^{*}=$ of least importance, $2^{*}=$ slightly important, $3^{*}=$ of average importance, $4^{*}=$ very important, $5^{*}=$ absolutely necessary 
Table 3

Priorities in PDs; 'Ranking' (Round 2) including top scoring subsections within each domain $^{a}$.

\begin{tabular}{|c|c|c|}
\hline $\begin{array}{l}\text { Overall } \\
\text { rank* }\end{array}$ & $\begin{array}{l}\text { Ranked Primary Domains } \\
\quad \text { Highest ranked subsections within each domain }\end{array}$ & STD Mean Rank ${ }^{*} \pm$ SD \\
\hline $1^{*}$ & $\begin{array}{l}\text { Economic evaluation/cost-effectiveness studies } \\
\text { • Cost benefit analyses of } O H \text { services }\end{array}$ & $\begin{array}{l}\mathbf{4 . 2} \pm \mathbf{2 . 6} \\
3.8 \pm 0.9\end{array}$ \\
\hline $1^{*}$ & $\begin{array}{l}\text { Disability management } \\
\text { - Functional capacity evaluation/Objective measures of disability assessment } \\
\text { - Attitudes towards disability in the workplace- employer and employee* }\end{array}$ & $\begin{array}{l}\mathbf{4 . 2} \pm \mathbf{2 . 5} \\
4.3 \pm 2.0 \\
4.3 \pm 2.1\end{array}$ \\
\hline 2 & $\begin{array}{c}\text { Occupational disease / injury/ illness } \\
\text { Work related mental ill health }\end{array}$ & $\begin{array}{l}4.9 \pm 2.6 \\
3.0 \pm 3.4\end{array}$ \\
\hline 3 & $\begin{array}{l}\text { The changing nature of work (including types of work and technology changes) } \\
\text { C Changing nature and patterns of work (e.g. flexible hours, remote working, zero hour } \\
\text { contracts, migrant workers, subcontractors, growth of self-employment) }\end{array}$ & $\begin{array}{l}\mathbf{5 . 5} \pm \mathbf{3 . 6} \\
3.0 \pm 1.7\end{array}$ \\
\hline 4 & $\begin{array}{l}\text { Health services research } \\
\quad \text { Best practice/benchmarking }\end{array}$ & $\begin{array}{l}\mathbf{5 . 6} \pm \mathbf{2 . 7} \\
3.6 \pm 1.1\end{array}$ \\
\hline 5 & $\begin{array}{l}\text { Occupational hazards to health and risk assessment } \\
\quad \text { Psycho-social hazards }\end{array}$ & $\begin{array}{l}\mathbf{5 . 7} \pm \mathbf{2 . 6} \\
4.0 \pm 2.2\end{array}$ \\
\hline 6 & $\begin{array}{l}\text { Occupational rehabilitation (including return to work after sickness absence) } \\
\text { - Evidence based guidelines on assessing fitness for work }\end{array}$ & $\begin{array}{l}\mathbf{5 . 8} \pm \mathbf{2 . 7} \\
4.2 \pm 1.5\end{array}$ \\
\hline 7 & $\begin{array}{l}\text { Health promotion } \\
\cdot \quad \text { Evaluation of effectiveness of programmes (in terms of engagement, productivity, } \\
\text { behaviour change, barriers to success) }\end{array}$ & $\begin{array}{l}\mathbf{6 . 2} \pm \mathbf{2 . 8} \\
3.3 \pm 1.3\end{array}$ \\
\hline 8 & $\begin{array}{l}\text { Sickness absence management } \\
\quad \quad \text { Effectiveness of interventions to keep employees at work }\end{array}$ & $\begin{array}{l}\mathbf{6 . 2} \pm \mathbf{2 . 9} \\
3.4 \pm 0.9\end{array}$ \\
\hline 9 & $\begin{array}{l}\text { Occupational health policy } \\
\text { - Development of evidence-based guidelines }\end{array}$ & $\begin{array}{l}\mathbf{6 . 7} \\
3.3 \pm \mathbf{2 . 5} \\
3.2\end{array}$ \\
\hline
\end{tabular}

Low scores indicate high priority and high scores indicate low priority

***

Both PD and SD were ranked equally highest

${ }^{a}$ Please note: PD and SD rank scores are not directly comparable but comparisons across PD and SD ranks scores are possible. 